\title{
Migrant experiences of living with type 2 diabetes in Western Sydney, Australia: a multilingual pilot research project
}

\author{
Christian Tyma,b, Ali Aldahesha, Irene Shidong Anª, Nesrine Basheer ${ }^{a}$, \\ Novi Djenara, Vek Lewis ${ }^{a}$, Dyah Pitaloka ${ }^{a}$, Antonia Rubino ${ }^{a}$ and \\ Wei Wanga
}

a School of Languages and Cultures, University of Sydney, NSW, Australia

b Corresponding author: christian.tym@sydney.edu.au

\section{Article history}

Publication date: June 2021

Citation: Tym C, Aldahesh A, An IS,

Basheer N, Djenar N, Lewis V, Pitaloka D,

Rubino A, Wang W. Migrant experiences of living with type 2 diabetes in Western Sydney, Australia: a multilingual pilot research project. Public Health Res Pract. 2021;31(2):e3122109 https://doi. org/10.17061/phrp3122109

\section{Background}

Home to almost 2 million people, Western Sydney is one of the most culturally and linguistically diverse regions in Australia: $32.7 \%$ and $39.4 \%$ of the population in the primary health administrative areas of South Western and Western Sydney respectively were born in a non-English-speaking country. ${ }^{1}$ Registers of diabetes diagnosis in Australia suggest greater incidence of type 2 diabetes among migrants. ${ }^{2}$ Migrants may also be underdiagnosed ${ }^{3,4}$, and are known to face additional challenges in managing chronic illnesses. ${ }^{5}$ The prevention and management of diabetes in Western Sydney therefore requires addressing a complex interrelationship of physiological, cultural, social and economic factors.

Much qualitative research addresses prevention and management of diabetes in migrant groups, particularly in the United States ${ }^{6}$, however Australian-based research is lacking. Moreover, much of this research predominantly sees culture in terms of group-specific "health beliefs" and "cultural behaviours"7, or in terms of "collective cultural and health beliefs, attitudes and assumptions". ${ }^{8}$ Although this work is important and valuable, it has the potential to overlook the culture of everyday life - that is, the ways in which migrants' new lives may differ from what may be considered typical of an ethnocultural group - as well as the health effects of migration trajectories and life histories themselves.

In an effort to contribute to further developing this body of research, a multilingual team of humanities and social science researchers was formed at the School of Languages and Cultures at the University of Sydney. Working with Arabic and Chinese speakers, the two most significant non-Englishspeaking migrant populations in Western Sydney ${ }^{9}$, our pilot project focused on their challenges in health management before, during and after their diagnosis with type 2 diabetes. 


\section{Methods}

A central element of this study was for all data collection to be done in the participants' native language by researchers who shared a cultural background with participants. Following COREQ guidelines ${ }^{10}$, one field research team included one female and one male Chinese researcher and the other included one female Egyptian and one male Iraqi researcher. In each team, one researcher's expertise was in sociolinguistics and the other's expertise was in language teaching and translation. The project team's other five members are all experienced in either sociolinguistics or health-related social sciences.

Participants were recruited via researchers' connections in the community, and the study was promoted in interviews and announcements in inlanguage local radio and print media. Participants resided in locations across Western and South Western Sydney. All participants were first-generation migrants aged more than 45 years old who predominately spoke Chinese or Arabic and who had been diagnosed with type 2 diabetes. Ultimately, nine in-person interviews were carried out with Arabic speakers and 10 with Chinese speakers, in each case at a location of their choice near their homes. Participants were interviewed about their understanding of health; their everyday experience of diabetes since diagnosis; any 'critical incident' relating to their diabetes; experiences with medical and allied health services; social support and self-management in informal contexts; as well as demographic information regarding their living situation, year of migration, country of origin, year of diabetes diagnosis and confidence speaking English.

In formulating our methodology, we drew inspiration from a number of participatory, community-based, culture-centred approaches to research. ${ }^{11-14}$ We sought to create space for participants to be able to discuss psychosocial dimensions of their wellbeing, culturally specific concepts of health and illness, and elements of informal health knowledge and care. Thus, research procedures were designed to cover multiple modalities of representation. The interviews were followed by group workshops: four Arabic-speaking men participated in a workshop, while five Chinese speakers participated in a mixed-gender workshop.

In the workshops, the participants represented their experiences via such tools as 'lifelines' - life history timelines focusing on migration, illness and other significant life events - and 'body maps' - visual selfrepresentations that locate the lived experience of health problems in different parts of the body. This multimedia approach facilitated a diversity of cultural and individual preferences regarding self-representation.

All interviews and workshops were recorded and transcribed, and these transcripts were then either translated or read into English in data sessions held between the research team. Data was then analysed and thematised using a grounded theory approach. ${ }^{15}$

\section{Human research ethics and informed consent}

All interactions with participants took place in their native language, or a mix of English and their native language if participants felt more comfortable doing so. Participant information sheets and consent forms were all in Chinese or Arabic, and introductory discussions about what would be involved in the research were extensive. Ethics approval was obtained from the Human Research Ethics Committee at the University of Sydney (protocol no. 2017/773).

\section{Findings}

A number of themes arose in the Arabic-speaking cohort: the severity of stress provoked by certain health communication strategies employed by frontline health practitioners; being unable to follow a diabetesappropriate diet due to lack of money; their capacity for successful diabetes management being associated with positive psycho-emotional states and social support networks, and conversely, the association of poorer selfmanagement with 'ghorba' (roughly, homesickness and loneliness); and, lastly, the experiential connection of the deterioration of their health with the trauma of migration itself. This last issue was particularly evident in the case of forced migrants from Iraq and Kuwait, some of whom spent time in immigration detention.

In contrast, Chinese migrants tended not to focus on the stress of migration itself or traumatic incidents leading up to migration, but on the stress of re-establishing themselves financially in their new country. This was exacerbated by the sense of loss of one's networks and connections ('guanxi'). As such, during their early years post-migration, health concerns tended to become a low priority. Chinese participants were also much more likely to be sceptical of medical science and employ traditional medicine than Arabic speakers. Overall though, the most prominent theme in Chinese participants' accounts was the diversity of understandings and approaches to diabetes management.

\section{Discussion}

These preliminary findings implicate a broader set of personal and socio-cultural dynamics than are often contemplated in behavioural risk factor analyses of ethnoculturally defined groups. ${ }^{16-18}$ As such, the research contributes to recent qualitative work that illustrates, in a non-reductive manner, the significance of culture for prevention and management of chronic illnesses. ${ }^{19,20}$ At the same time, our findings raise the possibility that this emphasis in recent qualitative work on migrants' culture needs to be complemented by other social and interpersonal factors beyond ethnocultural 
specificities. Advocates of such a position have often pointed instead to the adverse health consequences of the structural economic position of migrants. ${ }^{21-23}$ Our preliminary findings accord with this work, but also highlight the psychosocial effects of experiences leading up to emigration, as well as migration and resettlement itself. ${ }^{24}$ While this finding remains to be borne out in more extensive research, it does suggest that it may be valuable for policy makers and practitioners in multicultural health to ensure that an emphasis on cultural competence does not obscure an appreciation of individuals' life histories and their effects on chronic illness and self-management.

\section{Acknowledgements}

The pilot project was enabled by Faculty of Arts and Social Sciences Compact Funding from the University of Sydney.

\section{Peer review and provenance}

Externally peer reviewed, not commissioned.

\section{Competing interests}

None declared.

\section{Author contributions}

$\mathrm{CT}, \mathrm{AR}$ and $\mathrm{VL}$ were responsible for the design, drafting, analysis of data, and editing of the manuscript. ND and DP provided analytical advice, reviewing and editing for the manuscript. AA, NB, ISA and WW collected data and contributed to data analysis and drafting of the manuscript.

\section{References}

1. Public Health Information Development Unit, Torrens University. Social health atlas of Australia: data by Primary Health Network. Adelaide: PHIDU; 2020 [cited 2020 Jul 15]. Available from: phidu.torrens.edu.au/socialhealth-atlases/data

2. Jowsey T, Gillespie J, Aspin C. Effective communication is crucial to self-management: the experiences of immigrants to Australia living with diabetes. Chronic IIIn. 2011;7(1):6-19

3. Neal D, Magwood G, Jenkins C, Hossler CL. Racial disparity in the diagnosis of obesity among people with diabetes. J Heal Care Poor Underserved. 2006;17(2):106-15.

4. Diaz E, Kumar BN. Differential utilization of primary health care services among older immigrants and Norwegians: a register-based comparative study in Norway. BMC Health Serv Res. 2014;14(1):623-32.
5. Rose VK, Harris MF. Experiences of self-management support from GPs among Australian ethnically diverse diabetes patients: a qualitative study. Psychol Health Med. 2015;20(1):114-20.

6. Jone V, Crowe M. How people from ethnic minorities describe their experiences of managing type-2 diabetes mellitus: a qualitative meta-synthesis. Int J Nurs Stud. 2015;76(1):78-91.

7. Choi TST, Walker KZ, Ralston RA, Palermo C. Diabetes education needs of Chinese Australians: a qualitative study. Health Educ J. 2015;74(2):197.

8. Alzubaidi H, McNamara K, Kilmartin GM, Kilmartin JF, Marriott J. The relationships between illness and treatment perceptions with adherence to diabetes selfcare: a comparison between Arabic-speaking migrants and Caucasian English-speaking patients. Diabetes Res Clin Prac. 2015;110(2):215.

9. SMH.com. Sydney's melting pot of language. Sydney: Sydney Morning Herald; 2014 [cited 2020 Jul 14]. Available from: www.smh.com.au/interactive/2014/ sydney-languages/

10. Tong A, Sainsbury P. Consolidated criteria for reporting qualitative research (COREQ): a 32-item checklist for interviews and focus groups. Int J Qual Health Care. 2007;19(6):349-57.

11. Berthold T, ed. Foundations for community health workers. Hoboken, NJ: Wiley; 2016.

12. Dutta MJ. Communicating health: a culture-centred approach. London: Polity Press; 2008.

13. Schim SM, Doorenbos A, Benkert R, Miller J. Culturally congruent care: putting the puzzle together. J Transcult Nurs. 2007;18(2):103-10.

14. Cornwall $A$, Jewkes $R$. What is participatory research? Soc Sci Med. 1995;41(12):1667-76.

15. Charmaz K. Constructing grounded theory: a practical guide through qualitative analysis. London: Sage; 2006.

16. Gupta SS, Aroni R, Teede H. Experiences and perceptions of physical activity among South Asian and Anglo-Australians with type 2 diabetes or cardiovascular disease: implications for clinical practice. Qual Heal Res. 2017;27(3):391-405.

17. Shamshirgaran SM, Jorm L, Bambrick H, Hennessy A. Country-of-birth differences in adverse health behaviours among people with type 2 diabetes. Aust NZ J Public Health. 2015;39(3):250.

18. Sarich PEA, Ding D, Sitas F, Weber MF. Co-occurrence of chronic disease lifestyle risk factors in middle-aged and older immigrants: a cross-sectional analysis of 264,102 Australians. Prev Med. 2015;81:209-15.

19. Iwelunmor J, Newsome V, Airhihenbuwa CO. Framing the impact of culture on health: a systematic review of the PEN-3 cultural model and its application in public health research and interventions. Ethn Health. 2014;1(1):20-46. 
20. Avgoulas M-I, Fanany R. Religion as a means of resilience and adjustment to chronic illness. Int $\mathrm{J}$ Health Wellness Society. 2013;2(2):45-51.

21. Viruell-Fuentes EA, Miranda PY, Abdulrahim S. More than culture: structural racism, intersectionality theory, and immigrant health. Soc Sci Med. 2012;75(12):2099-106.

22. Castañeda $H$, Holmes SM, Madrigal DS, DeTrinidad Young M-E, Beyeler N, Quesada J. Immigration as a social determinant of health. Annu Rev Public Health. 2015;36:375-92.
23. Australian Institute of Health and Welfare. Indicators of socioeconomic inequalities in cardiovascular disease, diabetes and chronic kidney disease. Canberra, Australia: AlHW; 2019 [cited 2020 Jul 15]. Available from: www. aihw.gov.au/reports/social-determinants/indicatorssocioeconomic-inequalities/summary

24. Thurston WA, Vissandjée B. An ecological model for understanding culture as a determinant of women's health. Crit Public Health. 2005;15(3):229-42.

\section{Copyright: (c) (i) (2)}

(C) 2021 Tym et al. This article is licensed under the Creative Commons Attribution-NonCommercial-ShareAlike 4.0 International Licence, which allows others to redistribute, adapt and share this work non-commercially provided they attribute the work and any adapted version of it is distributed under the same Creative Commons licence terms. See: www.creativecommons.org/licenses/by-nc-sa/4.0/ 